\title{
Posterior subtalar joint synoviography and corticosteroid injection in rheumatoid arthritis
}

\author{
F. BEAUDET AND A. ST. J. DIXON
}

From the Royal National Hospital for Rheumatic Diseases, Bath, England

SUMMARY Ten posterior subtalar joints of 8 patients with rheumatoid arthritis and 12 posterior subtalar joints of 6 cadavers were studied by contrast synoviography. In the rheumatoid group the abnormalities included posterior capsule distension, filling defects caused by hypertrophic synovitis, limited or irregular filling of the anterior recess of the joint in 5 out of 10 , and communication with the ankle joint in 3 out of 10 . None of the cadaveric joints showed posterior capsule distension or limited or irregular filling of the anterior recess of the joint, but communication with the ankle was present in 2 joints. The joints of the patients were injected with a $1: 1$ mixture of sodium iothalamate $70 \%$ (Conray 420) and triamcinolone hexacetonide (Lederspan) $20 \mathrm{mg} / \mathrm{ml}$. All patients noticed a decrease in and an improvement in walking beginning 24-48 hours after the examination. Quantitative thermography was done immediately before and 1 after injection in 2 patients who showed an improvement in thermographic index. We conclude that hindfoot inflammatory pain arising from the posterior subtalar joint is caused by distension with hypertrophic synovitis which can be difficult to detect clinically.

The subtalar joints function as a single unit but are anatomically separated into anterior (talo-calcaneo-navicular) and posterior (talo-calcaneal) joints. ${ }^{1}$ Inversion and eversion of the foot take place at these joints. ${ }^{2}$ Rheumatoid arthritis can cause synovitis in both joints and in early disease produces pain in the perimalleolar region on resting, weight bearing, or walking. With persistent involvement inflammatory changes lead to ligament laxity, allowing weight bearing forces to produce plantar and medial talar subluxation. The os calcis becomes laterally displaced, giving a valgus deformity of the mid and hind foot, ${ }^{3}$ an all too common outcome and one which is potentially preventable.

Contrast synoviography has been studied in most diarthrodial joints. The technique provides information on cavity size, synovial membrane changes, cartilage thickness and integrity, connections with cysts, tendon sheaths, and bursae. ${ }^{45}$ Synovial rupture and ligamentous tears can also be detected. ${ }^{6-9}$ Synoviography of the posterior subtalar joints has previously been studied in cadavers and normal individuals. $^{10-12}$ We report a study of posterior subtalar joint synoviography in rheumatoid arthritis.

Accepted for publication 13 May 1980

Correspondence to Dr A. St J. Dixon, Royal National Hospital for Rheumatic Diseases, Upper Borough Walls, Bath BA1 1RL.

\section{Material and methods}

Eight patients with classical or definite rheumatoid arthritis (American Rheumatism Association criteria) and 6 cadavers known not to have clinical joint disease in life were studied. Two patients and all the cadavers had both joints investigated (Table 1). Synoviography was performed for hindfoot pain at rest or on weight bearing and pain on inversion or eversion of the foot. Other limb joints were examined and any disease activity noted. Cadavers were studied no later than 36 hours after death. Lateral radiographs of the ankle were taken prior to synoviography.

The patient was asked to lie face downwards. The

Table 1 Clinical and biological data

\begin{tabular}{|c|c|c|}
\hline & Female & Male \\
\hline Total patients & 6 & 2 \\
\hline Total subtalar joints & 7 & 3 \\
\hline Mean age & $\begin{array}{l}44 \cdot 5 \\
(24-55)\end{array}$ & $\overline{(52,63)}$ \\
\hline Mean duration of disease & $\begin{array}{l}10 \cdot 5 \\
(2-17)\end{array}$ & $\frac{(0,001)}{(2,1)}$ \\
\hline Rheumatoid factor positive & 3 & 1 \\
\hline or/and feet & $\begin{array}{l}6 \\
3\end{array}$ & $\begin{array}{l}1 \\
3\end{array}$ \\
\hline Mean age & 81 & $83 \cdot 3$ \\
\hline
\end{tabular}


subtalar joint was approached laterally. The point of entry was located at the intersection of a line drawn $2.5 \mathrm{~cm}$ above the distal end of the fibula and a line drawn $1.0 \mathrm{~cm}$ from and parallel to the posterior border of the shaft of the fibula (Fig. 1). A $4 \mathrm{~cm} 21$ gauge or $3 \mathrm{~cm} 23$ gauge needle was introduced at a $60^{\circ}$ angle to the skin surface, the needle being pointed towards the proximal end of the first metatarsal and penetrating the soft tissue until cartilage was felt (Fig. 2). Aspiration was attempted-but fluid seldom obtained-before injecting a mixture of sodium iothalamate $70 \%$ (Conray 420) and triamcinolone hexacetonide (Lederspan) $20 \mathrm{mg}$ per $\mathrm{ml}$ into the posterior subtalar joint by a strictly aseptic, no-touch technique. Nonweight-bearing lateral and medial oblique $x$-rays of the ankle were taken immediately after injection with a GEC D55 unit using a $0.6 \mathrm{~mm}$ beam source and recorded on Ilford screen films (Ilfex Rapid R). Cadaveric joints were assessed with a portable Philips Super Practix machine using a $2.0 \mathrm{~mm}$ beam

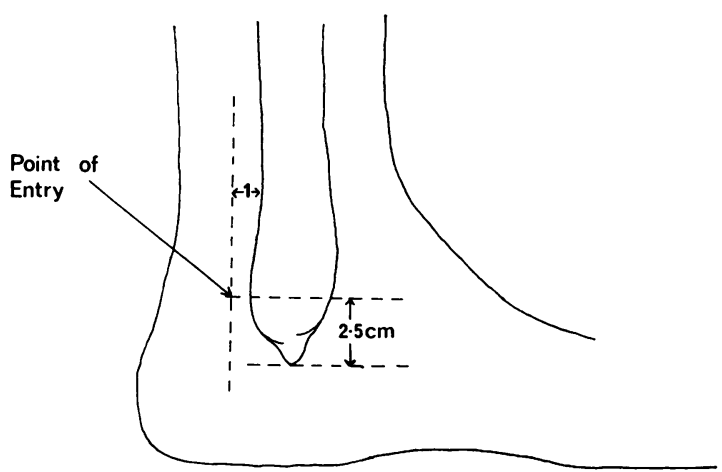

Fig. 1 Surface marking for point of entry for posterior subtalar joint injection. source. Meglumine iothalamate $60 \%$ (Conray 280) was used without corticosteroid.

\section{Results}

The majority of patients had polyarticular, erosive arthropathy and all had forefoot involvement (Table 1). The knees were involved in 7 , the midfeet in 6 , the ankles in 4 , and the hips in 2 patients respectively. The volume of fluid which was injected into the posterior subtalar joints of patients and cadavers varied between 2 and $3 \mathrm{ml}$.

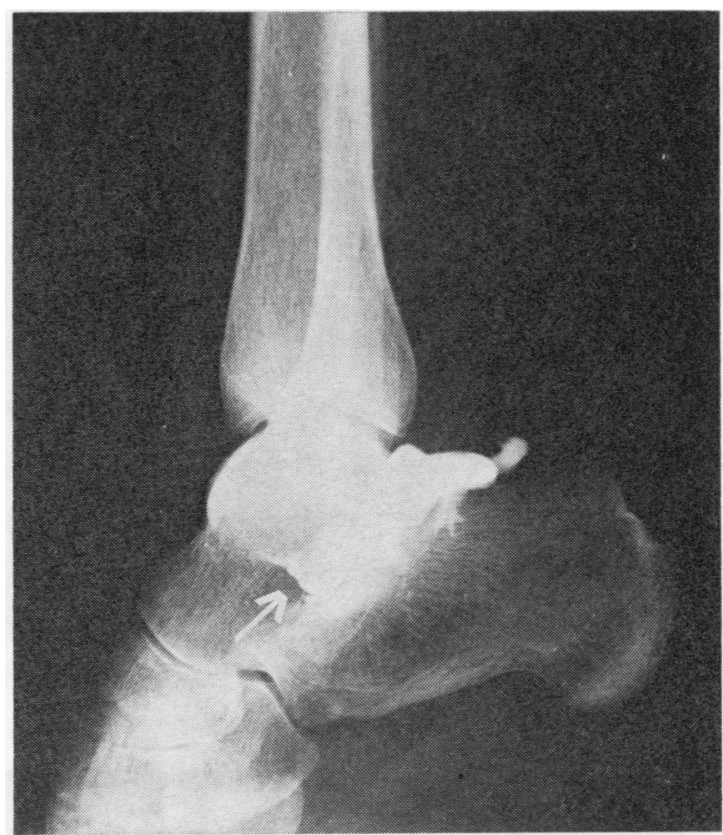

Fig. 3 Normal $V$ indentation of the posterior capsule in the subtalar joint (arrow).

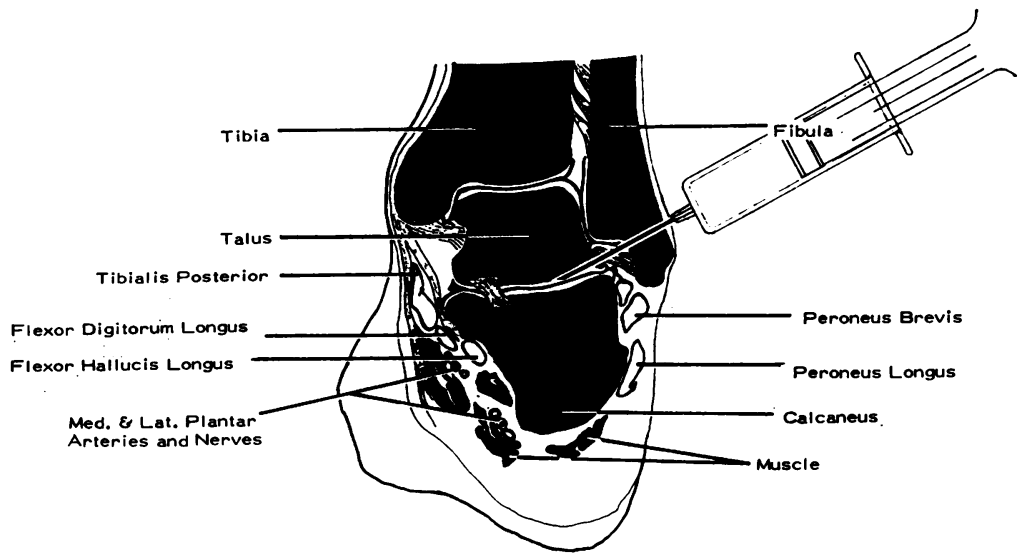

Fig. 2 Anatomy of the hindfoot. 
In the cadaveric control synoviograms filling of the anterior part of the posterior subtalar joint was a constant finding (Fig. 3). The posterior recess of the joint showed a V shape indentation in seven of 12 synoviograms (Fig. 4). Two of the 12 cadaveric subtalar joints communicated with the ankle.

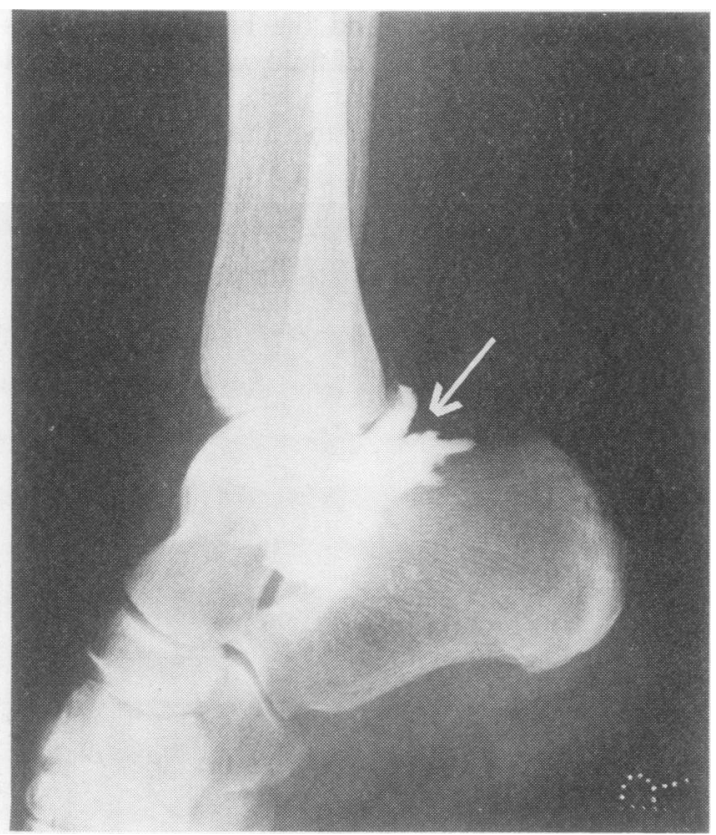

Fig. 4 Normal filling of anterior recess in subtalar joint of cadaver (arrow).

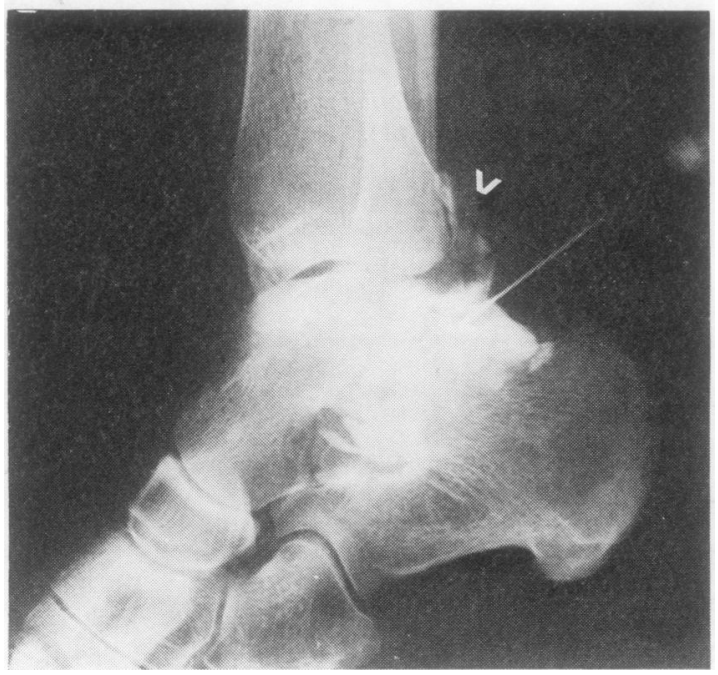

Fig. 5 Vertical distension of posterior capsule with filling defects in 20-year-old patient (arrow head).
The abnormal features found in the patients with rheumatoid arthritis are shown in Table 2. Distension of the posterior recess was present in all synoviograms. The distension was directed vertically or more posteriorly, accentuating the $\mathrm{V}$ shape noted in the control group (Fig. 4). The distended capsule showed filling defects corresponding to hypertrophic synovitis in all joints (Figs. 5 and 6). The anterior compartment of the joint either showed irregular filling or obliteration in 6 of 10 patients (Fig. 7). Prompt drainage of contrast material through the lymphatics was detected in 4 patients. Three subtalar joints communicated with the ankle. All patients noticed less pain at rest and on weight bearing within 24 to 48 hours. Walking was reported to be easier.

Table 2 Arthrographic findings in normal and rheumatoid patients

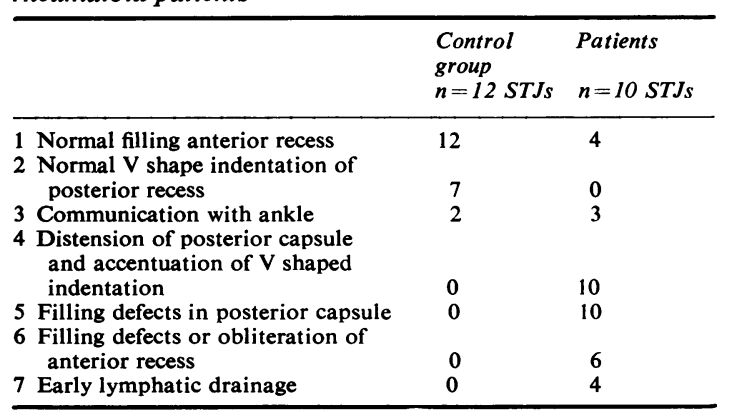

STJ = subtalar joint .

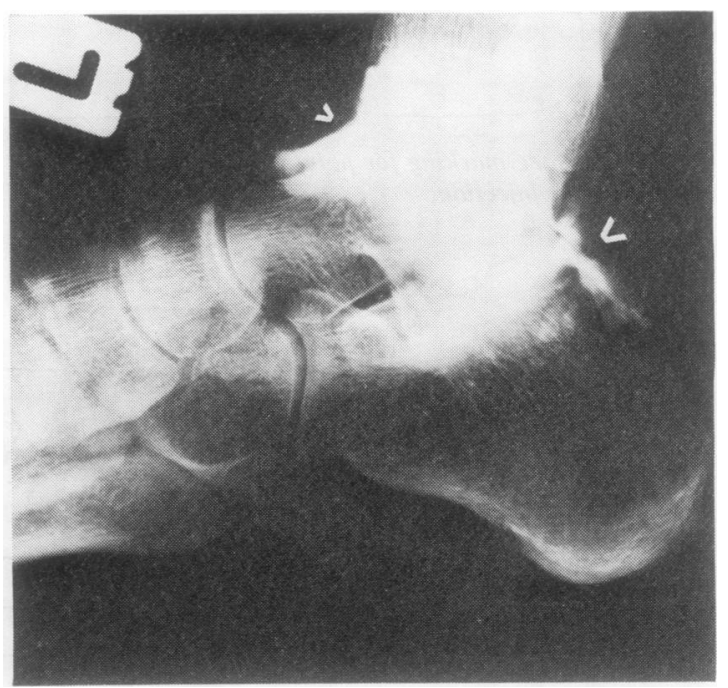

Fig. 6 Accentuation in V shape capsule in 42-year-old patient (large arrow head); note also communication with ankle (small arrow head). 


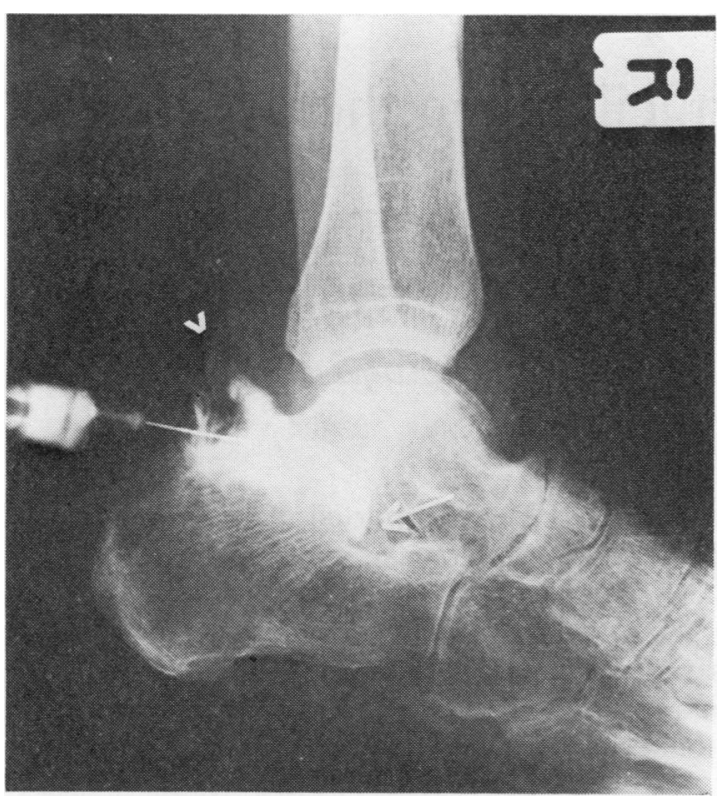

Fig. 7 Irregular outline and lack of anterior recess filling (arrow). Early lymphatic drainage (small arrow head) in 52-year-old patient.

In 2 patients with rheumatoid arthritis the thermographic index ${ }^{1314}$ was estimated before and 1 week after synoviography and corticosteroid injection and in each instance showed improvement.

\section{Discussion}

Synoviography of diarthrodial joints requires moderate technical skill. It is a useful diagnostic procedure to investigate joint and periarticular abnormalities. Synoviography of the posterior subtalar joint by a lateral approach has the advantage that no major blood vessels and nerves are likely to be traversed by the injecting needle. However, when the patient has a severe valgus deformity it may be difficult to obtain an adequate synoviogram. A radiograph taken after a small preliminary injection of contrast material can help direct the needle if there is such a difficulty.

The posterior subtalar joint can accept only a very small volume of fluid unless it communicates with the ankle. The synoviography technique has proved repeatable with practice. The posterior recess normally present has a $\mathrm{V}$ shaped indentation which is probably related to adipose tissue in the supracalcaneal and sub-Achilles tendon area. ${ }^{15}$ The ligaments binding the talus to the os calcis are strong anteriorly and laterally and prevent capsule distension in these regions, so that when intraarticular pressure is raised by the increased secretion of synovial fluid from the rheumatoid synovial proliferation the $\mathrm{V}$ shape indentation is accentuated (Figs. 5, 6, 7). Rapid lymphatic drainage has previously been reported and is thought to be secondary to increased synovial permeability. ${ }^{12}$

The mixture of a corticosteroid with the radiographic contrast material gives an adequate concentration of anti-inflammatory drug delivered into the joint. All patients reported benefit from this treatment, and no complications were encountered. The anti-inflammatory effect was confirmed in 2 patients by means of the thermographic index.

We are grateful to Drs John Cosh and Paul Bacon for allowing us to examine their patients, to Dr John Lever for allowing us to study cadavers, and to the Arthritis and Rheumatism Council for a block grant.

\section{References}

1 Tracy E G. Definition of the subtalar and transverse tarsal joints. J Am Podiatry Assoc 1974; 64: 56-8.

2 Shephard E. Tarsal movements. J Bone Joint Surg 1951; 33B: $258-63$.

3 Vainio K. The rheumatoid foot: a clinical study with pathological and roentgenological comments. Chir Gynaecol Fenn 1956; 45: Suppl 1.

4 Gerber N G, Dixon A St J. Synovial cysts and juxtaarticular bone cysts. Semin Arthritis Rheum 1974; 3: 323-47.

5 Dixon A St J, Rasker J J. Synoviography. Clin Rheum Dis 1976; 2: 129-47.

6 Dixon A St J, Grant C. Acute synovial rupture in rheumatoid arthritis. Lancet 1964; i: 742-5.

7 Spiegel P K, Staples O S. Arthrography of the ankle joints. Common problems in diagnosis of acute lateral ligament injuries. Radiology 1975; 114: 587-90.

8 Scott D G I, Schlecht B J M. Anterior synovial rupture of ankle joint presenting as deep venous thrombosis. $\mathrm{Br} \mathrm{Med}$ $J$ 1979; i: 1766.

9 Fernandez L, Goodwill C G, Srivtvatsa S R. Synovial rupture of rheumatoid elbow causing radial nerve compression. Br Med J 1979, ii: 17-8.

10 Weston W G. Synovial lesions of the midtarsal and posterior subtaloid joints in rheumatoid arthritis. Aust Radiol 1972; 16: 84-8.

11 Resnick D. Radiology of talo-calcaneal articulation. Radiology 1974; 111: 581-6.

12 Hug G, Dixon A St J. Ankle joint synoviography in rheumatoid arthritis. Ann Rheum Dis 1977; 36: 532-9.

13 Bird $\mathbf{H}$ A, Ring E F J, Bacon P A. Thermographic and clinical comparison of three intra-articular steroid preparations in rheumatoid arthritis. Ann Rheum Dis 1979; 38: 36-9.

14 Ring E F J. La thermographie des affections osteoarticulaires non traumatiques du pied. 1980; in press.

15 Davies D V, Davies F. Gray's Anatomy. London: Longmans, $1964 ; 558$. 